\title{
Las instrucciones notariales
}

\author{
Joel González Castillo*
}

\begin{abstract}
RESUMEN
Este artículo aborda la importante cuestión de las instrucciones notariales. Debido a la complejidad de los contratos modernos, el mayor número de partes que intervienen en los contratos y la creciente cuantía de los mismos, se ha vuelto común que junto con la suscripción del contrato principal las partes otorguen instrucciones al notario para los más diversos efectos, no circunscribiéndose actualmente esas instrucciones -como era usual- solo a la entrega del precio al vendedor cuando se cumplen determinados requisitos (por ejemplo, inscripción en el Conservador de Bienes Raices). De abi la necesidad de clarificar su naturaleza jurídica, valor probatorio, carácter vinculante y limites.
\end{abstract}

$$
\text { Instrucciones - mandato - notarios }
$$

\section{Notarial Instructions}

\begin{abstract}
This paper addresses the important topic of notarial instructions. Due to the complexity of modern contracts, the larger number of parties involved on them and the increasing amounts of the businesses, it has become that along with the subscription of the main contract the parties grant instructions to the notary for the most diverse purposes, without being such instructions circumscribed -as it was the case- only to the payment of the price to the seller upon fulfillment of certain requirements (e.g., inscription on the Real Estate Registry). Hence the need for clarifying, among other issues, its legal nature, evidentiary weight, binding force and limits.
\end{abstract}

$$
\text { Instructions - mandate - notaries }
$$

* Magíster en Derecho de la Unión Europea, Universidad Complutense de Madrid. Magíster en Derecho de la Empresa, Pontificia Universidad Católica de Chile. Profesor de Derecho Civil, Pontificia Universidad Católica de Chile. Correo electrónico: jagonzac@uc.cl.

El autor agradece los aportes y revisiones a este artículo de Francisco Micheli Basualto, ayudante del Depto. de Derecho Civil de la PUC.

Artículo recibido el 24 de abril de 2015 y aceptado para su publicación el 30 de agosto de 2016. 


\section{INTRODUCCIÓN}

$\mathrm{E}$ 1 uso corriente de las instrucciones notariales unido a su no reglamentación, y la forma muchas veces poco clara de su redacción, hacen imperioso su estudio. Es llamativo al respecto la escasa doctrina y jurisprudencia acerca del tema, no obstante que hoy prácticamente no hay contratos o actos de importancia que no vayan acompañados de estas instrucciones notariales ${ }^{2}$. En este artículo abordamos aspectos relevantes de ellas, como su naturaleza jurídica, valor probatorio, su eficacia para modificar escrituras públicas previas, la utilidad interpretativa de las mismas, la responsabilidad de los notarios si no las cumplen adecuadamente, la posibilidad que los notarios se conviertan de facto en árbitros al darles cumplimiento, y otros.

Para Vidal las instrucciones notariales son una manifestación de voluntad que en un instrumento, normalmente aparte de una escritura pública (también puede ser privada), suscriben los otorgantes del contrato, o alguno de ellos que tienen un interés correspondiente, en orden a que el ministro de fe, a quien se hace depositario por lo general de dinero o valores, cumpla con los encargos que se le cometen, en tanto ocurra el vencimiento de un plazo, se cumpla una condición o se verifique el cumplimiento de ciertos requisitos, según ha quedado determinado por los interesados ${ }^{3}$. Agrega el mismo autor que habitualmente ellas son anexas a la celebración de contratos como la compraventa, en los que se hace entrega al notario del dinero, valores o documentos que constituyen el pago del precio, y que este debe entregar al vendedor cuando, por ejemplo, se ha cumplido el trámite de la inscripción de dominio a nombre del comprador. Pueden, no obstante, asumir diversas otras formas y ser aplicables a cualquier otro acto o contrato. Donde se encuentra de forma más habitual, sin embargo, es en las compraventas de inmuebles. No tienen una reglamentación ni específica ni general en

${ }^{2}$ El proyecto de ley sobre notarios y conservadores en actual tramitación en el Congreso en concordancia con lo que señalamos dice: "La realización de instrucciones y confección de actas, son tareas de habitual ocurrencia en notarías. Sin embargo, ellas no cuentan con reconocimiento ni regulación legal. La importancia de estos instrumentos, y la sentida necesidad de uniformar los criterios para materializar estas actuaciones conforme a derecho, impulsan a la presente iniciativa legal a cumplir con estos objetivos, dando contenido y formalidades de obligado cumplimiento a estas gestiones" y "La custodia de valores o documentos representativos de pago es también una actuación diaria en los oficios que no tiene reconocimiento legal. Esta falta de reconocimiento positivo no solo evidencia un desfase entre la práctica notarial y la legalidad, sino también resta regulación idónea al desarrollo de esta actividad de común exigencia que obligue a los notarios a actuar bajo patrones comunes de resguardo y procedimiento para su ejercicio. En atención a lo dicho, el proyecto intenta definir las instrucciones a la luz de los aportes efectuados en ese sentido por nuestra jurisprudencia, señalando la manera en que ellas deben consignarse y ejecutarse y la debida correspondencia de su contenido con nuestro ordenamiento jurídico". Vid Mensaje N 171-360, de S.E. el Presidente de la República con el que inicia un "Proyecto de Ley que Incorpora Modificaciones al Régimen de Nombramiento y Funciones del Sistema Notarial y Registral", Santiago, 3 de octubre de 2012, Boletín $N^{\circ} 8673-07$, pp. 8-9, 18-19, disponible en http://www.senado.cl/appsenado/templates/tramitacion/index.php. Complementa este proyecto aquel otro de que da cuenta el Mensaje No 176-361, de S.E. el Presidente de la República con el que inicia un "Proyecto de Ley que Moderniza y Fortalece el Funcionamiento y la Fiscalización del Sistema Registral y Notarial”, Santiago, 6 de agosto de 2013, Boletín $N^{o}$ 9059-07. Este último proyecto no trata materias relativas a las instrucciones notariales.

${ }^{3}$ Vidal, I., El Estudio de los Títulos de Dominio. Segunda Parte, Editorial Fallos del Mes Ltda., Santiago, 2000 , p. 12. 
la ley y se han convertido en la actualidad en una práctica tan habitual que casi no hay compraventa de inmuebles en que no se pacten estas instrucciones ${ }^{4}$.

Como cuestión previa a la naturaleza jurídica de las instrucciones digamos que la revisión de muchas de ellas ${ }^{5}$ nos indica que las instrucciones suelen quedar plasmadas en un instrumento privado, en general con la forma de un acta que da cuenta de los encargos y custodias que recibe el notario, el que se suscribe por todas o algunas de las partes que intervienen en ellas. El original de este instrumento privado queda en poder del notario para su incorporación al "libro de instrucciones" que lleva la notaría, comúnmente foliado, mientras que los instructores reciben copia del mismo. En cuanto a su contenido, los términos de este instrumento son en general fijados por los mismos instructores, en ocasiones con la intervención del Ministro de Fe o, más comúnmente, de funcionarios de la notaría.

\section{Naturaleza jurídica}

Respecto de la naturaleza jurídica de las instrucciones existen en doctrina diversas posturas que en síntesis se pueden agrupar fundamentalmente en dos grupos; unos que las ven como un acto más del notario en el ejercicio de su función pública y otros que consideran que se trata de contratos (aunque discuten su tipo).

\section{Instrucciones notariales como ejercicio de una función pública del notario. Las instrucciones notariales no serían contrato. Argumentos}

Esta tesis parte de la base que el notario interviene en las instrucciones notariales no como contratante sino como órgano que ejerce una función pública, la notarial, reduciéndose con ello el debate a si las instrucciones notariales están o no comprendidas dentro del catálogo de facultades del artículo 401 del Código Orgánico de Tribunales ${ }^{6}$.

${ }^{4}$ Cfr., Vidal, I., El Estudio de los Títulos de Dominio, T. I, El Jurista, Santiago, 2012, p. 72.

${ }^{5}$ Para efectos de este trabajo nos constituimos en diversas notarias pudiendo encontrar instrucciones notariales de hasta ¡16 carillas!, de suyo complejas, que las convierten en verdaderas escrituras paralelas y en algunas ocasiones en abierta contradicción con lo acordado en la escritura pública previa. Igualmente pudimos comprobar que las instrucciones notariales que se contienen en lo que se denomina el Libro de Instrucciones en la mayoría de los casos no son firmadas por el Notario e incluso no siempre son suscritas por todas las partes que concurrieron al otorgamiento de la escritura pública anterior.

${ }^{6}$ Art. 401. Son funciones de los notarios:

1. Extender los instrumentos públicos con arreglo a las instrucciones que, de palabra o por escrito, les dieren las partes otorgantes;

2. Levantar inventarios solemnes;

3. Efectuar protestos de letras de cambio y demás documentos mercantiles;

4. Notificar los traspasos de acciones y constituciones y notificaciones de prenda que se les solicitaren;

5. Asistir a las juntas generales de accionistas de sociedades anónimas, para los efectos que la ley o reglamento de ellas lo exigieren;

6. En general, dar fe de los hechos para que fueren requeridos y que no estuvieren encomendados a otros funcionarios; 
Para quienes entienden las instrucciones comprendidas dentro de la función pública notarial, el Notario, tanto en la instrucción como en la escritura pública o en cualquier acto, interviene como funcionario que obra por delegación del poder público pero no comparece propiamente como una parte contratante. Respecto del Notario, la instrucción es un acto como cualquier otro que le encomiendan las leyes y le da cumplimiento en su calidad de ministro de $\mathrm{fe}^{7}$. En este orden de ideas, se ha dicho que la instrucción notarial no sería una institución regulada directa o propiamente por la legislación civil porque en sus aspectos más relevantes pertenece al Derecho Público ${ }^{8}$. En definitiva, esta doctrina otorga a las instrucciones notariales el carácter de función pública, negándole por tanto al notario instruido la calidad de contratante y al acto mismo la naturaleza de contrato civil.

¿Están las instrucciones notariales dentro de las funciones que el COT en su artículo 401 señala como propias de los notarios? Un primer grupo sostiene que las instrucciones aun siendo una función pública no se encuentran dentro de las actuaciones que enumera el artículo $401^{9}$. Se cita en apoyo un fallo de la Corte de Apelaciones de Santiago que declara que: las instrucciones que se dan al notario por quienes solicitan sus servicios, no se encuentran comprendidas dentro del ámbito de las funciones de dicho Ministro de Fe. Ninguna norma legal se refiere expresamente a ellas y no aparecen consignadas en la enumeración de facultades a que alude el artículo 401 del Código Orgánico de Tribunales ${ }^{10}$; y otro de la misma Corte que resolvió: las instrucciones que los particulares dan a los Notarios constituyen comisiones de confianza de carácter privado, no descritas entre las atribuciones que la ley les otorga como ministros de fe $e^{11}$.

Para salvar el hecho que las instrucciones no están en el art. 401 citado podría -dicen- recurrirse a la costumbre como fuente de normas que rigen la actuación notarial. Este ha sido el criterio de algunos respecto de otros casos de falta de regulación sistemática de la actuación notarial ${ }^{12}$. Así, Gaete señala que en tales casos la actuación

7. Guardar y conservar en riguroso orden cronológico los instrumentos que ante ellos se otorguen, en forma de precaver todo extravío y hacer fácil y expedito su examen;

8. Otorgar certificados o testimonios de los actos celebrados ante ellos o protocolizados en sus registros;

9. Facilitar, a cualquiera persona que lo solicite, el examen de los instrumentos públicos que ante ellos se otorguen $y$ documentos que protocolicen;

10. Autorizar las firmas que se estampen en documentos privados, sea en su presencia o cuya autenticidad les conste;

11. Las demás que les encomienden las leyes.

7 Torrealba, V., La instrucción notarial: su naturaleza jurídica, Tesis para optar al grado de licenciado en derecho de la Pontificia Universidad Católica de Chile, 2001, p. 30.

${ }^{8}$ Ídem.

${ }^{9}$ Ídem, pp. $25-26$

${ }^{10}$ Corte de Apelaciones de Santiago, 22 de noviembre de 2000, Rol de Protección No 3934-2000, cons. $3^{\circ}$.

${ }^{11}$ Corte de Apelaciones de Santiago, 26 de septiembre de 1988, Rol 207-88.

${ }^{12}$ Autores como Vidal defienden esta particular aplicación directa de la costumbre en materia notarial señalando que al igual que en materia mercantil, la función notarial está sujeta a constantes cambios y a tener que dar respuestas rápidas a las exigencias de la actividad del comercio, Cfr. Vidal, I., El Estudio de los Títulos de Dominio. Segunda Parte, Editorial Fallos del Mes Ltda., Santiago, 2000, p. 14. En razón de ello, señala el mismo autor: "ante los vacíos o no respuestas que entregan las ramas tradicionales del Derecho 
notarial queda sujeta a los usos y costumbres imperantes, basados generalmente en la aplicación, por extensión, de principios generales relativos a otros actos del ministro de fe y que normalmente se refieren a la interpretación por adecuación de las normas que sobre escrituras públicas contempla el Código Orgánico de Tribunales ${ }^{13}$. Más aún, para el mismo Gaete las instrucciones notariales constituyen justamente una situación en la que los usos notariales cobran plena aplicación, y en la que es posible apreciar la considerable importancia y utilidad de estos usos en el diario quehacer de una escribanía ${ }^{14}$.

Una segunda postura, contraria a la anterior, estima que las instrucciones notariales sí se encuentran reguladas dentro de las atribuciones que señala el Código Orgánico de Tribunales. Algunos las estiman comprendidas en el numeral $7^{\circ}$ del artículo 401, que encomienda a los notarios guardar y conservar en riguroso orden cronológico los instrumentos que ante ellos se otorguen, en forma de precaver todo extravio y hacer fácil y expedito su examen. En tal sentido, algunos de estos instrumentos que debe guardar el notario serían justamente las instrucciones que se le encarguen, así como los documentos que las acompañen ${ }^{15}$. Otros enmarcan las instrucciones notariales en la atribución del numeral $6^{\circ}$ de la misma disposición, esto es, En general, dar fe de los hechos para que fueren requeridos y que no estuvieren encomendados a otros funcionarios, entendiendo que muchas veces las instrucciones recibidas les imponen la obligación de verificar la ocurrencia de ciertos hechos, como lo es el cumplimiento de una condición o la llegada de un plazo ${ }^{16}$.

Considerar que las instrucciones son un acto de la función pública del notario nos merece al menos dos reparos. En primer lugar, ninguna de las funciones designadas en el artículo 401 del Código Orgánico de Tribunales satisface por completo las características de las instrucciones notariales, y todo intento de encuadrarlas en algún numeral de dicho catálogo obliga a realizar interpretaciones forzadas de las mismas. Además, al tratarse de una enumeración de atribuciones legales de un órgano que ejerce una función pública, los principios que rigen el ejercicio de toda potestad pública llevan necesariamente a entender el artículo 401 como taxativo ${ }^{17}$. En segundo lugar, se ha fallado que los Notarios no están obligados a aceptar las instrucciones que puedan impartírseles ${ }^{18}$, lo que

a la actuación de oficio del Notario, es natural que la costumbre recorra dichos despachos y se enseñoree demostrando su vigencia, utilidad y conveniencia, a través de lo que se ha de conocer como 'los usos' o 'practicas notariales”. Ídem, p. 14.

13 Gaete, E., Actas Notariales. Parte General, Editorial La Ley, Santiago, 1993, p. 15.

${ }^{14}$ Ídem, p. 18.

${ }^{15}$ Vid Díaz, L., Derecho Notarial Chileno, Editorial Jurídica de Chile, Santiago, 1983, p. 218.

16 Torrealba, V., La instrucción notarial: su naturaleza jurídica, Tesis para optar al grado de licenciado en derecho de la Pontificia Universidad Católica de Chile, 2001, p. 26.

${ }^{17}$ Lo que se denomina Libro de Instrucciones, tampoco está entre los libros que deben llevar los notarios conforme a los artículos 429 y siguientes del mismo Código. La única referencia expresa a las instrucciones se encuentra en el Decreto $\mathrm{N}^{\circ} 587$ de Justicia de 1998 sobre "Arancel de los Notarios Públicos" que en su artículo $1^{\circ} \mathrm{N}^{\circ} 16$ señala: "Instrucciones: por cada instrucción en el Libro respectivo, el arancel será convencional”.

${ }^{18}$ Corte de Apelaciones de Santiago, 22 de noviembre de 2000, Rol de Protección N ${ }^{\circ}$ 3934-2000, cons. $4^{\circ}$. 
implica una discrecionalidad que resulta en alguna medida incompatible con el ejercicio de una función pública.

Hay que agregar que entre quienes estiman el otorgamiento de las instrucciones comprendido dentro de la función pública del notario, se sitúan aquellos que sostienen que ellas serían esencialmente Actas Notariales.

Las Actas Notariales, según señala Gaete, pueden ser definidas por exclusión como todo instrumento público notarial, emanado de competente notario y que no tiene carácter de escritura pública ${ }^{19}$ y trata como actas notariales de depósito a los "Libros de Instrucciones hechas al Notario" no previstos por la Ley pero vigentes en los Oficios Notariales y que se refieren al depósito que se efectúa a estos, generalmente como consecuencia de pactos que tienen lugar en escrituras públicas, referidos a saldos de precios en compraventas $u$ otros documentos o efectos ${ }^{20}$.

\section{Las instrucciones notariales serian contrato}

En oposición a las tesis anteriores sostenemos que las instrucciones son un contrato, pues constituyen un acuerdo de voluntades entre quien o quienes acuden a los servicios notariales -instructores-y el ministro de fe -instruido-, que crea obligaciones para todos ellos. Estas características dan a las instrucciones notariales la calidad de contratos en los términos del artículo 1438 de nuestro Código Civil (concretamente, a nuestro juicio, un contrato de mandato como desarrollaremos luego).

Las instrucciones por regla general tendrán la calidad de contratos bilaterales (pago de un arancel por la realización del encargo) ${ }^{21}$. Por otra parte, se encuentran entre aquellos contratos que la doctrina denomina dependientes. Al respecto, López Santa María dice que se denomina dependientes a ciertos contratos que están supeditados a otra convención, pero sin garantir su cumplimiento ${ }^{22}$, cuestión esta última que los diferencia de los contratos accesorios. Es evidente que las instrucciones notariales están supeditadas a un contrato previo -que generalmente consta en una escritura pública-, pero no están destinadas a garantizar su cumplimiento, de ahí que se las pueda calificar como contratos dependientes, y si bien en la práctica ellas se usan mayoritariamente para dar seguridad ${ }^{23}$ al cumplimiento de las obligaciones de una de las partes de un contrato previo, las instrucciones no pueden calificarse como garantías o cauciones, pues el notario no contrae ninguna obligación para "la seguridad de otra obligación propia o ajena" (art. 46 del Código Civil). Es cierto que el notario asume la obligación, por

${ }^{19}$ Gaete, E., Actas Notariales. Parte General, Ediciones Jurídicas La Ley, 1993, p. 34.

${ }^{20}$ Idem, p. 121.

${ }^{21}$ En el mismo sentido se pronuncia Rosso, G., "Instrucciones notariales como comisiones de confianza", en Henríquez, I. (coord.), El Mandato. Ensayos doctrinarios y comentarios de jurisprudencia, LegalPublishing, Santiago, 2013, p. 86.

${ }^{22}$ López Santa María, J., Los Contratos. Parte General, T. I, Editorial Jurídica de Chile, 2005, p. 128.

${ }^{23}$ En el mismo sentido Pizarro, C., "La responsabilidad civil de los notarios en Chile", en Revista de Derecho Universidad Católica del Norte, Año 18-Nº 2, 2011 , p. 146. 
ejemplo, de entregar los valores una vez inscrito el bien en el Conservador de Bienes Raíces, pero se trata de documentos o valores proporcionados por las propias partes.

\subsection{Instrucciones notariales como depósito}

Se podría argüir que como el notario muchas veces recibe en custodia dinero, valores o documentos representativos de dinero estaríamos en presencia de un depósito. Pero ello no es así, pues por definición en el depósito el depositario debe restituir la cosa a voluntad del depositante y a este mismo (art. 2215 del Código Civil). Por el contrario, en las instrucciones que analizamos esos dineros o valores solo se entregan por el Notario cuando se han cumplido determinadas circunstancias o requisitos y a una parte que no es generalmente la que los ha entregado previamente al notario.

Otra dificultad que observamos para otorgar a las instrucciones notariales la calificación de depósito es el carácter gratuito de este, lo que no parece compatible con las instrucciones por las cuales siempre se cancela un arancel ${ }^{24}$.

Estimamos que la entrega de dineros o valores al notario constituye -en línea con nuestra tesis que las instrucciones son un mandato- una de las obligaciones del mandante: "proveer al mandatario de lo necesario para la ejecución del mandato" (art. 2158 $\mathrm{N}^{\circ} 1$ del Código Civil). Sin aportar mayores fundamentos, Stitchkin también niega el carácter de depósito a las instrucciones ${ }^{25}$.

\subsection{Instrucciones notariales como estipulaciones en favor de otro}

Como se sabe, en virtud de la estipulación en favor de otro, un contrato celebrado entre dos partes que reciben el nombre de estipulante y promitente hace nacer un derecho a favor de un tercero ajeno a él, llamado beneficiario ${ }^{26}$. Es posible, entonces, distinguir tres categorías de sujetos: a) el estipulante, que es quien contrata en favor de un tercero, b) el promitente, quien se compromete a favor del tercero en la calidad de deudor de este, y c) el beneficiario, que es el acreedor de la estipulación efectuada en su favor.

Considerando lo anterior, podría sostenerse que en aquellos casos de instrucciones notariales en que una parte encarga al notario la entrega de documentos o valores a un tercero (generalmente la otra parte de un contrato previo) que no comparece en ellas (luego se explicará que las instrucciones pueden ser suscritas por todas o algunas del partes de ese contrato previo), el instructor sería el estipulante, el notario sería el promitente y ese tercero, el beneficiario de la estipulación.

Aceptando que las instrucciones notariales pueden revestir en algunos casos el carácter de estipulaciones en favor de otro, ello sin embargo no representa un avance para determinar qué figura contractual son, pues la estipulación en favor de otro puede tener lugar

\footnotetext{
${ }^{24}$ En el mismo sentido, Torrealba, V., La instrucción notarial: su naturaleza jurídica, Tesis para optar al grado de licenciado en derecho de la Pontificia Universidad Católica de Chile, 2001, p. 50.

${ }^{25}$ Stitchkin, D., El Mandato Civil, Editorial Jurídica de Chile, Santiago, 2013, p. 93.

${ }^{26}$ Vid por todos Abeliuk, R., Las Obligaciones, Editorial LegalPublishing, Santiago, 2014, p. 168.
} 
en cualquier clase de $\operatorname{contratos}^{27}$ y además porque, es posible recordar, la estipulación no es propiamente un contrato, sino que es una excepción al efectivo relativo de los mismos.

\subsection{Instrucciones notariales como comisiones de confianza}

Un fallo del Pleno de la Corte de Apelaciones de Santiago otorgó a las instrucciones notariales el carácter de comisiones de confianza en los siguientes términos: Atendido el mérito de los antecedentes, lo informado por el Notario recurrido y considerando que las instrucciones que los particulares dan a los Notarios constituyen comisiones de confianza de carácter privado, no descritas entre las atribuciones que la ley les otorga como ministros de fe, y no apareciendo en los antecedentes falta o abuso... ${ }^{28}$.

En línea con esta jurisprudencia el proyecto de ley relativo a notarios y conservadores citado incorpora un artículo 439 ter al Código Orgánico de Tribunales que señala: La custodia de valores o documentos representativos de pago que se entreguen a un notario con motivo u ocasión de la celebración de un acto o contrato, y mediante instrucciones escritas, constituye un encargo o comisión de confianza que obliga a aquél, en caso de aceptarla, a cumplirla en la forma $y$ condiciones que las partes otorgantes le han indicado ${ }^{29}$.

Respecto de esta postura, tiene mucho sentido lo razonado por Rosso en cuanto a que asignar a una figura con poco desarrollo doctrinal como las instrucciones notariales, la denominación de "comisiones de confianza", tradicionalmente referida a encargos efectuados a bancos, no genera avance alguno, sino por el contrario, confusión ${ }^{30}$. En cuanto al fondo, el mismo autor sostiene categóricamente que las instrucciones no constituyen comisión de confianza, pues estas implican una administración de bienes destinados a una finalidad; y los Notarios, por medio de las instrucciones notariales, no administran patrimonios afectados ${ }^{31}$.

\subsection{Instrucciones notariales como servicio profesional}

Otros autores, entre ellos Rosso, sostienen que las instrucciones notariales serían sencillamente la contratación, por parte de los instructores, de un servicio profesional

${ }^{27}$ Ídem.

${ }^{28}$ Corte de Apelaciones de Santiago, 26 de septiembre de 1988, Rol 207-88. La Corte Suprema conociendo de la apelación de dicho acuerdo recaído en un reclamo administrativo lo confirmó (Corte Suprema, sentencia de 18 de noviembre de 1988). En el mismo sentido vid Corte Suprema, 9 de septiembre de 1988, reclamo administrativo, Fallos del Mes, No 358 (1988), p. 608.

${ }^{29}$ Mensaje cit., p. 38.

${ }^{30}$ Para Rosso “la calificación de tratarse de 'comisiones de confianza' no genera avance alguno, sino por el contrario, confusión, pues en Chile no existe en realidad un régimen jurídico particular denominado 'comisiones de confianza' al que puedan someterse las IN (instrucciones notariales)" y "Las 'comisiones de confianza' en nuestro país constituyen exclusiva e históricamente encargos efectuados a bancos”, Rosso, G., "Instrucciones notariales como comisiones de confianza", en Henríquez, I. (coord.), El Mandato. Ensayos doctrinarios y comentarios de jurisprudencia, LegalPublishing, Santiago, 2013, p. 78.

${ }^{31}$ Ídem, p. 85. 
particular ofrecido en los oficios notariales ${ }^{32}$, respecto de esto se aplicarían indirectamente las disposiciones relativas al mandato de acuerdo con el Código Civil. Agrega el mismo autor que si bien las instrucciones notariales involucran un encargo, no tendrían el carácter personal que exige el mandato, sino solo un carácter profesional, y no obstante ser negocios de confianza, esta recaería más que en la persona del notario, en la clase de profesión por él ejercitada en cuanto implica la delegación de la fe pública por parte del Estado en los Notarios. De esta manera -continúa- si bien los contratos de prestación de servicios profesionales liberales se encuentran en Chile sometidos por el Código Civil a las disposiciones del mandato, en el entendido que en dichos servicios concurre igualmente el carácter intuito personae, en principio, a las instrucciones notariales no se les deberían aplicar las mismas normas por escapar a dicha lógica. Sin embargo, concluye que se hace forzoso aplicar a las instrucciones las normas del mandato, pero únicamente "por vía indirecta", esto es, por aplicación analógica, debido a lo exiguo de la reglamentación acerca de arrendamiento de servicios profesionales ${ }^{33}$.

\subsection{Instrucciones notariales como mandato}

En nuestro criterio las instrucciones notariales son mandatos, sin perjuicio de las particularidades que la naturaleza de los contratantes y de su objeto les imponen.

Decimos que las instrucciones son un mandato, pues por ellas se confiere un encargo (art. 2116 del Código Civil) al notario cuyo objeto será aquel que las partes le instruyan concurriendo los elementos distintivos de todo mandato, esto es, la confianza ${ }^{34}$, la gestión de uno o más negocios ${ }^{35}$, y que tal gestión sea realizada por cuenta o riesgo del mandante. En favor de su naturaleza de mandato, aunque sin dar mayor fundamento, se pronuncia Stitchkin, quien al distinguir el mandato del depósito afirma que el notario a

\footnotetext{
32 Ídem, p. 94.

33 Ídem, pp. 94-95.
}

${ }^{34}$ La confianza es elevada al nivel de elemento esencial del mandato y así se ha sostenido: "En el contrato de mandato lo esencial es la confianza que deposita el mandante en su mandatario", Riveros, C., "El principio general de la buena fe en el contrato de mandato. Comentario a la sentencia de la Corte Suprema de 30 de mayo de 2012, Rol N 5229-09”, en Henríquez, I. (coord.), El Mandato. Ensayos doctrinarios y comentarios de jurisprudencia, LegalPublishing, Santiago, 2013, p. 210. Agreguemos para destacar la presencia de esta confianza en las instrucciones notariales que si en ellas las partes eligen a un notario para confiarle determinadas gestiones es, entre otros motivos, en consideración a su calidad legal de ministro de fe y su formación jurídica. Como señala Rosso, los instructores "recurren a estos (los notarios) como auxiliares de la administración de justicia a los que se les ha encomendado un rol social de elevada importancia como es resguardar la fe pública", Rosso, G., "Instrucciones notariales como comisiones de confianza", en Henríquez, I. (coord.), El Mandato. Ensayos doctrinarios y comentarios de jurisprudencia, LegalPublishing, Santiago, 2013, p. 85.

${ }^{35}$ Uno de los varios objetos que puede tener el mandato es la ejecución de un negocio jurídico. Dice Stitchkin: "Distínguese el negocio jurídico del negocio económico en que en el primero el mandatario tiene como obligación principal ejecutar un acto o celebrar un contrato (...). En el primer caso (negocio jurídico) el mandatario cumple su obligación y le pone término ejecutando el acto o celebrando el contrato...", Stitchkin, D., El Mandato Civil, Editorial Jurídica de Chile, Santiago, 2013, p. 45. Así, por ejemplo, en una típica instrucción notarial en que el Notario debe entregar dinero o valores a una de las partes cumplidas ciertas condiciones, esa entrega constituye la ejecución del negocio que se le ha encomendado. 
quien el comprador de la cosa le entrega el precio para que lo pague al vendedor una vez saneada la propiedad, es un mandatario ${ }^{36}$.

Respecto del perfeccionamiento de este contrato, bien podría sostenerse que, debido a que generalmente el Notario no suscribe las instrucciones, no cabría hablar de mandato pues faltaría la voluntad de este, pero es del caso recordar que conforme al art. 2124 del Código Civil el contrato de mandato se reputa perfecto por la aceptación del mandatario, y aceptación tácita es todo acto en ejecución del mandato, lo que es plenamente aplicable al Notario, que al dar cumplimiento a las instrucciones manifiesta tácitamente su aceptación del encargo que se le ha hecho. Esta aceptación tácita sin la comparecencia del mandatario (Notario) en el instrumento (instrucción), en la práctica resulta ser la regla general de perfeccionamiento del mandato y es lo que explica que quien fija el contenido del mandato es el mandante, al confiar la gestión de uno o más negocios al mandatario, describiendo aquel o aquellos y definiendo, con más o menos extensión, las facultades de que dispondrá el mandatario ${ }^{37}$.

Que las instrucciones sean un mandato es una idea resistida por parte de la escasa doctrina que se ha pronunciado al respecto, basando su negativa en los razonamientos que pasamos a exponer y controvertimos.

a) Se ha sostenido que en las instrucciones notariales muchas veces la parte instructora está constituida por una o más personas, y estas a menudo son antagonistas en el acto principal, presentando intereses contrapuestos en lo que respecta al cumplimiento de las instrucciones $^{38}$. En tal escenario, ante un conflicto entre las partes instructoras, la decisión del notario de ejecutar las instrucciones en tal o cual sentido beneficiaría a un instructor y perjudicaría de modo inversamente proporcional al otro u otros ${ }^{39}$, lo que sería contrario al artículo 2149 del Código Civil, que ordena al mandatario abstenerse de cumplir el mandato cuya ejecución sea manifiestamente perniciosa para el mandante.

En contra se ha señalado que tratándose de la ejecución de un mandato que perjudica al mandante, su sanción se sujeta al principio o regla general que establece la indemnización de perjuicios del mandatario al mandante, sin que pueda advertirse otro tipo de sanción jurídica para este caso ${ }^{40}$. Partiendo de esta premisa, en cuanto a que la responsabilidad del mandatario derivada del artículo 2149 del Código Civil no es otra que una responsabilidad por infracción a los términos del

${ }^{36}$ Ídem, p. 93.

37 Vidal, Á.-Brantt, M., "Obligación, incumplimiento y responsabilidad civil del mandatario en el Código Civil chileno”, en Revista Chilena de Derecho, vol. 40, N² (2013), p. 417.

${ }^{38}$ Rosso, G., "Instrucciones notariales como comisiones de confianza”, en Henríquez, I. (coord.), El Mandato. Ensayos doctrinarios y comentarios de jurisprudencia, LegalPublishing, Santiago, 2013, p. 89.

39 Ídem.

${ }^{40}$ Sáenz de Santa María, F., "Extralimitación del mandatario”, en AA. VV., Contratos, Editorial Jurídica de Chile, Santiago, 1991, p. 40. En el mismo sentido Stitchkin, D., El Mandato Civil, Editorial Jurídica de Chile, Santiago, 2013, p. 398. 
mandato, es posible concluir que en caso que el notario ejecute las instrucciones de un modo perjudicial a uno de los instructores habría incumplimiento con la consiguiente responsabilidad contractual, pero en caso alguno ello impide afirmar la naturaleza de mandato de las instrucciones.

b) Además, se dice que es común que habiéndose otorgado instrucciones a tal o cual notario, estas sean cumplidas no por la misma persona, sino por el notario suplente o interino. Este "reemplazo" temporal o definitivo de la persona natural que ejerce las funciones de notario, que está regulado expresamente por la ley con el fin de obtener una continuidad en el trabajo notarial, sería contrario a la calidad de contrato intuito personae del mandato. Esto lleva a sostener que las instrucciones notariales no son un contrato intuito personae (como si lo es, en cambio, el mandato), dado que se contrata con quien ejerce una calidad jurídica por delegación estatal en un oficio notarial, y no con una persona natural individual ${ }^{41}$.

c) Por último, para negar la calidad de mandato de las instrucciones notariales se afirma que ciertas causales de terminación del mandato les son inaplicables. Por ejemplo, no es concebible la renuncia del notario al encargo una vez asumido, o la pérdida de vigencia de las instrucciones en razón de su muerte considerando que quien lo suceda igualmente las cumplirá, ni tampoco aplicaría como causal de terminación la muerte de uno de los instructores. En tal sentido Rosso dice que teniendo lugar las situaciones anteriores, en la práctica no han existido dudas que las instrucciones notariales mantienen toda su vigencia, y en caso de muerte de los instructores, los derechos y obligaciones se transmiten a sus herederos. La razón jurídica se encuentra, a su juicio, en el hecho de que las instrucciones notariales no son un contrato intuito personae ${ }^{42}$.

Como se puede apreciar, los postulados contenidos en las letras b) y c) niegan a las instrucciones notariales el carácter de mandato, pues no serían contratos intuito personae. El problema de esa corriente es que entiende el carácter intuito personae como algo asociado solo a las personas naturales, cuestión que no es así; piénsese por ejemplo en las comisiones de confianza que se otorgan a un banco; en ellas se hace el encargo a tal banco y no a otro por la confianza que ese banco en particular otorga al mandante independiente de quién sea en ese momento su gerente general. La confianza, propia del mandato, por tal razón, puede recaer tanto en una persona natural como en entidades, cual es el caso de las notarías. En las instrucciones notariales el mandato se otorga más que al notario mismo a una determinada notaría. Así, si bien la persona que ejerza la función notarial puede cambiar (notario titular, suplente o interino), ello no altera que el encargo haya sido encomendado a una específica notaría. Sostenemos que las instrucciones notariales son intuito personae, ya que siempre serán cumplidas por la misma notaría, independiente

${ }^{41}$ Rosso, G., "Instrucciones notariales como comisiones de confianza”, en Henríquez, I. (coord.), El Mandato. Ensayos doctrinarios y comentarios de jurisprudencia, LegalPublishing, Santiago, 2013, p. 92.

${ }^{4}$ Ídem, p. 93. 
de quién esté ejerciendo las funciones de ministro de fe. Corrobora lo dicho el hecho de que si bien las instrucciones pueden ser cumplidas por personas distintas del notario instruido que ejerzan la función notarial en la misma notaría -suplentes o interinos-, no es admisible que la instrucción sea cumplida por otra notaría. En resumen, la confianza y el carácter intuito personae se pueden dar tanto en las personas naturales, jurídicas $(v$. $g r$. bancos-comisiones de confianza), o entidades de otra índole como las notarías.

Para reafirmar nuestra tesis, que las instrucciones son mandatos, nos permitimos recordar, como explicamos previamente, que en las instrucciones notariales concurren los elementos distintivos de todo mandato: confianza, la gestión de uno o más negocios, y que tal gestión sea realizada por cuenta o riesgo del mandante. Son estos tres elementos los que Stitchkin identifica precisamente como aquellos que le dan fisonomía al mandato ${ }^{43}$.

\section{LAS INSTRUCCIONES NOTARIALES EN CUANTO CONTRAESCRITURA}

Cualquiera sea la naturaleza jurídica que se dé a las instrucciones, ya que tienen una escritura pública como antecedente, procede entonces analizarlas en cuanto contraescrituras.

Respecto del concepto de contraescritura debe tenerse presente que existen en la doctrina y jurisprudencia opiniones encontradas. Para algunos, los términos amplios de la disposición del artículo 1707 del Código Civil debe comprenderse en el concepto de contraescritura a toda escritura o instrumento posterior en el que los otorgantes modifiquen o alteren en todo o parte, en sus elementos esenciales o accidentales, los contratos, sea para dejarlos sin efecto o para introducir cualquier modificación, ya sustancial o de detalle ${ }^{44}$. Así entendida, la contraescritura solo implicará simulación si el acto modificatorio está destinado a permanecer en secreto ${ }^{45}$. Para otros, es condición esencial para que un escrito constituya contraescritura el que tengan por objeto hacer constar la simulación total o parcial de un acto anterior ${ }^{46}$, en caso contrario habrá modificación o revocación de lo pactado, pero no contraescritura ${ }^{47}$.

En cuanto a las instrucciones notariales la Corte Suprema tuvo la oportunidad de analizar este punto al pronunciarse acerca de un caso en que junto a la escritura pública

43 Stitchkin, D., El Mandato Civil, Editorial Jurídica de Chile, Santiago, 2013, p. 48.

${ }^{44}$ Vid por todos Alessandri, A., De las Obligaciones, versiones taquigráficas de sus clases, Santiago, 1930 , p. 485 .

45 Abeliuk, R., Las Obligaciones, Editorial LegalPublishing, Santiago, 2014, p. 188.

${ }^{46}$ Corte Suprema, 27 de diciembre de 1945, Revista de Derecho y Jurisprudencia, t. 43, sec. 1a, p. 337 , cons. 15. En este sentido Claro, L., Explicaciones de Derecho Civil Chileno y Comparado, t. XII, Santiago, 1939, p. 687; Santa Cruz, V., "El instrumento público", en Revista de Derecho y Jurisprudencia, t. 39, primera parte, No 94, p. 54; Proyecto de Código Civil español de Francisco García Goyena, artículo 1214, citado en el Proyecto Inédito de Bello (art. 1882j) como fuente del artículo 1707 del Código Civil chileno. Los datos de esta cita han sido tomados de Repertorio de Legislación y Jurisprudencia Chilenas, Código Civil y Leyes Complementarias, T. VI, Editorial Jurídica de Chile, Santiago, 1997, p. 385.

${ }^{47}$ Abeliuk, R., Las Obligaciones, Editorial LegalPublishing, Santiago, 2014, p. 189. 
de compraventa de un inmueble las partes suscribieron unas instrucciones notariales en las que dejaron constancia de algunas deficiencias que presentaba ese inmueble, que la empresa vendedora se obligaba a subsanar, a su costa. La vendedora demandó ejecutivamente a la compradora el pago del saldo de precio y esta opuso, entre otras excepciones, la del artículo $464 \mathrm{~N}^{\circ} 7$ del Código de Procedimiento Civil, esto es, de carecer el título de los requisitos que prescribe la ley para que tenga fuerza ejecutiva. Los jueces del fondo no acogieron esta excepción, haciendo lugar a la demanda ejecutiva de la vendedora.

En el recurso de casación en el fondo interpuesto por la ejecutada y compradora de ese bien raíz, se argumentaba que ese instrumento privado (instrucciones notariales), suscrito por los contratantes, constituía una contraescritura que complementaba o modificaba lo pactado en la escritura pública de compraventa, por lo que los jueces del fondo al resolver lo contrario habían infringido los artículos 1707 , inciso $1^{\circ}$, del Código Civil, que regla y determina los efectos de esta clase de documentos, en relación con los artículos 1545, que establece que todo contrato legalmente celebrado es una ley para los contratantes, y 1439, al desconocer que las partes se obligaron recíprocamente, en virtud de esa constancia acerca de las reparaciones aún pendientes; asimismo al no darle ese carácter de contraescritura, habían violado también el artículo 1552 del Código Civil, que consagra el principio de que la mora purga la mora, y que impedía a la firma constructora cobrar por la vía ejecutiva el saldo de precio adeudado mientras no cumpliera con la obligación de ejecutar esas obras menores, y, consecuencialmente, el artículo 464, $\mathrm{N}^{\circ} 7$, del Código de Procedimiento Civil, porque el título carecía de fuerza ejecutiva por estar el ejecutante en mora y, por tanto, debía haberse acogido esta excepción rechazándose la demanda.

La Corte Suprema señala en primer lugar que debe entenderse por contraescritura, conforme al art. 1707 inc. $1^{\circ}$ del Código Civil, aquella escritura privada hecha por los contratantes para alterar lo pactado en escritura pública y que En la especie fluye, de su simple lectura, que aquel documento privado (instrucciones notariales) suscrito por las partes-vendedora y compradora- solo tuvo por finalidad dejar constancia de algunos detalles que aún quedaban por terminar en el departamento (...) y que la empresa constructora se comprometió a ejecutar, a su costa, sin que (...) las partes hayan pretendido complementar y modificar el contrato de compraventa, como sostiene la recurrente, ya que esa intención no se desprende, en forma alguna, de su contexto, pues es del todo evidente que esa constancia aparece desvinculada de las obligaciones y contenido de la compraventa, más aún si se tiene en cuenta la entidad y naturaleza de los trabajos que se hallaban pendientes, por lo que, a no dudarlo, solo tuvo el carácter de un instrumento privado que no alteraba, en absoluto, los efectos jurídicos de dicho contrato. Agrega la misma sentencia Que los jueces recurridos, al establecer (...) "que las instrucciones que las partes dejaron en poder del notario..., y suscritas con la misma fecha de la escritura de compraventa, no constituye una contraescritura..., puesto que ellas no alteran lo pactado en la escritura...", le dieron a esa constancia escrita su real y exacto alcance, de modo que al no aplicar el artículo 1707, inciso $1^{\circ}$, del Código Civil no quebrantaron esta disposición, sino que, al contrario, al no hacerlo, se ajustaron estrictamente al contenido de esta norma. Nuestro más alto tribunal concluye así: Que, por consiguiente, tampoco se han infringido los artículos 1545 y 1439 del Código Civil, ni los artículos 1552 de este cuerpo legal y 464 número 7, del Código de Procedimiento Civil, 
al no aplicarlos para resolver la controversia, toda vez que el recurso, en esta parte, se elabora en función de que ese documento privado constituye una contraescritura, y como quiera que se halla establecido que no tiene ese carácter, estas supuestas infracciones no ban podido producirse, por lo que el recurso entablado deberá desestimarse $e^{48}$.

Como se puede apreciar, la razón principal vertida por la Corte Suprema para negar a las referidas instrucciones notariales el carácter de contraescrituras es que no se desprendía del contexto de ellas la intención de las partes de modificar o complementar el contrato principal. A contrario sensu, siguiendo el razonamiento de la Corte Suprema, si las instrucciones notariales alteran las obligaciones y contenido del contrato previo, sí tendrían el carácter de contraescrituras al amparo del artículo 1707 del Código Civil.

\section{VOLUNTARIEDAd DE LA ACEPTACIÓN DE INSTRUCCIONES POR PARTE DEL NOTARIO}

La pregunta es: ¿podría en Chile un notario negarse a aceptar instrucciones notariales?

Responder esta interrogante exige previamente resolver otra: ¿el otorgamiento de instrucciones notariales es parte de las atribuciones que la ley -artículo 401 del COTencomienda al notario? En efecto, si las instrucciones notariales constituyesen una facultad que la ley o, según algunos, la costumbre notarial otorga al notario, no parece admisible que este pueda negarse a recibirlas, ya que serían parte de la función pública que ejerce.

Según nuestro parecer y en concordancia con la naturaleza jurídica que atribuimos a las instrucciones -mandato-, el notario es libre para aceptarlas o no en virtud de la libertad contractual que tiene y además porque, como explicamos anteriormente, la verdad es que el artículo 401 citado en ninguna parte señala como una de las funciones del notario el otorgamiento de instrucciones notariales. Aquellos que las ven comprendidas en esa norma hacen una interpretación forzada de sus numerales $6^{\circ}$ y $7^{\circ}$. Por último, existe jurisprudencia que establece en términos generales la facultad del notario de admitir o no instrucciones. Así, la Corte de Apelaciones de Santiago ha declarado que las instrucciones que se dan al notario por quienes solicitan sus servicios no se encuentran comprendidas dentro del ámbito de las funciones de dicho Ministro de Fe. Ninguna norma legal se refiere expresamente a ellas y no aparecen consignadas en la enumeración de facultades a que alude el artículo 401 del Código Orgánico de Tribunales (...) los Notarios no están obligados a aceptar las instrucciones que puedan impartírseles y en el evento que las llegaran a aceptar, su cumplimiento quedaría entregado a lo que cada uno de ellos estime prudente y equitativo ${ }^{49}$.

${ }^{48}$ Corte Suprema, Rol 18.532, 23 de agosto de 1993 , cons. $4^{\circ}, 5^{\circ}$ y $6^{\circ}$, Revista de Derecho y Jurisprudencia, t. 90 , sec. $1^{\text {a }}$, p. 86 .

${ }^{49}$ Corte de Apelaciones de Santiago, 22 de noviembre de 2000, Rol de Protección No 3934-2000, cons. $3^{\circ}$ y $4^{\circ}$ 


\section{CARÁCter VinCulante de las instrucciones PARA QUIENES LAS SUSCRIBEN}

Respecto de esto se ha resuelto: Que al recibir el Notario instrucciones sobre la forma en que debe cumplir los acuerdos de las partes, asume la obligación de ajustar su conducta a la forma establecida en ese momento por las partes, sin que ninguna de ellas pueda revocarlas o alterarlas en forma unilateral, aunque fuere en forma mínima y que Debe tenerse en consideración que la práctica de dejar en poder de los Notarios valores u otros documentos para ser entregados al cumplirse con determinados requisitos, ha servido y sirve, en innumerables oportunidades para llevar adelante negociaciones, lo que sería imposible si los señores Notarios se prestaran a variar, o aceptar que se variaran, las instrucciones recibidas al perfeccionarse los contratos ${ }^{50}$. Es decir, las instrucciones, si han sido otorgadas por ambas partes de la escritura previa adquieren también un carácter contractual entre las mismas, sin que puedan modificarse unilateralmente por una de ellas (pacta sunt servanda), de lo contrario las instrucciones carecerían de toda utilidad.

En concordancia con lo dicho, el proyecto de ley citado acerca de notarios y conservadores dispone en el inciso tercero del artículo 439 ter que se incorpora al Código Orgánico de Tribunales: Las instrucciones suscritas por las partes asumen la forma de un contrato entre ellas y solo podrán variarse mediante declaración suscrita ante notario y por los mismos otorgantes suscriptores del documento que se rectifica ${ }^{51}$. La misma norma en su inciso $6^{\circ}$ parte final agrega: Del mismo modo, no se aceptarán instrucciones suscritas por solo una parte, salvo que se trate de actos unilaterales, ofertas de pago u otros en que, a juicio del notario, no sea posible o necesaria la concurrencia de la otra parte ${ }^{52}$. Según nuestro parecer, nada obsta a que fuera de los casos señalados sea solo una de las partes quien otorgue las instrucciones, claro está sin ser vinculantes para la otra, debido a su no concurrencia. Para ilustrar lo que venimos diciendo tomemos como ejemplo la más común de las instrucciones: el comprador deja en poder del Notario el precio del bien adquirido para que se le entregue al vendedor una vez que este le exhiba el correspondiente Certificado del Conservador que acredite que la propiedad está libre de gravámenes y que se inscribió a nombre del comprador. Pueden suceder dos cosas. Una, que tales instrucciones sean firmadas por ambas partes, lo que no presentaría problema alguno. Segundo, que las mismas instrucciones solo sean

50 Se trataba de un caso en que un Notario se negaba a entregar un cheque a la parte vendedora -correspondiente a un saldo de precio-, no obstante que el mismo Notario había dejado constancia que esa parte había dado cumplimiento a las exigencias contenidas en las instrucciones; el Notario acogía así el planteamiento de la parte compradora en cuanto a que debía ser el árbitro designado en la escritura de compraventa quien debía decidir sobre la entrega del cheque. Además de ello, el caso revestía importancia porque había dualidad de instrucciones. Una, otorgada de común acuerdo entre vendedor y comprador, y otra posterior emanada solo del comprador por la cual sujetaba la entrega del cheque a la vendedora a nuevas condiciones. Corte de Apelaciones de Santiago, 27 de febrero de 1990, recurso de protección Cía. Pesquera de los Canales del Sur Limitada contra Aliro Veloso Muñoz, Rol 23-90, Fallos del Mes, N 376 (1990), p. 23 , cons. $3^{\circ}$ y $8^{\circ}$.

${ }^{51}$ Mensaje cit., p. 38.

52 Ídem. 
suscritas por el comprador. En principio, se podría pensar que ellas no revisten utilidad porque el comprador las podría revocar. Así lo estima Vidal, quien señala que para que las instrucciones obliguen a todos los involucrados en ellas, deben suscribirlas todos, pues, en caso contrario, no pasará más allá de un simple mandato unilateral susceptible de revocación, pudiéndose así burlarse más de un derecho de algún contratante de buena $\mathrm{de} \mathrm{fe}^{53}$. Sin embargo, siguiendo nuestra tesis que las instrucciones son un mandato, en el ejemplo estaríamos en presencia de uno otorgado por el comprador (al notario) en interés de un tercero (vendedor), y por lo mismo según se tiene aceptado por la doctrina no cabe la revocación (art. 241 del Código de Comercio) ${ }^{54}$. En resumen, sostenemos que estas “instrucciones unilaterales" no son vinculantes para la otra parte del contrato previo, es decir, tal como señala Vidal no resultarán obligados quienes no las hayan suscrito. Sin embargo, a diferencia de Vidal no creemos que estas instrucciones sean revocables si existe interés de un tercero como lo puede ser precisamente el de aquella otra parte que si bien concurrió a ese contrato previo no ha suscrito estas instrucciones posteriores.

\section{FORMA DE CUMPLIMIENTO DE LAS INSTRUCCIONES}

Acerca de este punto nos resulta particularmente interesante una sentencia que señala que es solamente al Notario a quien le corresponde decidir la forma en que cumple las instrucciones que recibio ${ }^{55}$. Otra, también en sede de protección, parece ir más allá al señalar: los Notarios no están obligados a aceptar las instrucciones que puedan impartírseles y en el evento que las llegaran a aceptar, su cumplimiento quedaría entregado a lo que cada uno de ellos estime prudente y equitativo, sin que la decisión que al respecto adopten pueda tildarse de ilegal o arbitraria ${ }^{56}$. No obstante los categóricos términos que usan ambas sentencias para otorgar amplias libertades al notario instruido, lo cierto es que este no tiene tal discrecionalidad en lo que se refiere al cumplimiento de las instrucciones. En efecto, el notario deberá, como todo mandatario, i) ceñirse rigurosamente y en primer lugar a los términos de las instrucciones (art. 2131 del C.C.), ii) por ser un mandato remunerado el notario ha de consultar a sus mandantes respecto de su correcta ejecución ${ }^{57}$, y iii) tener

53 Vidal, I., El Estudio de los Títulos de Dominio. Segunda Parte, Editorial Fallos del Mes Ltda., Santiago, 2000, p. 32.

${ }^{54}$ Vid el desarrollo de este tema en González, J., "Mandatos irrevocables: un cuestionamiento a su general aceptación”, en Elorriaga, F. (coord.), Estudios de Derecho Civil VII, LegalPublishing, Santiago, 2012, pp. 351-360.

${ }^{55}$ Corte de Apelaciones de Santiago, 27 de febrero de 1990, recurso de protección Cía. Pesquera de los Canales del Sur Limitada contra Aliro Veloso Muñoz, Rol 23-90, Fallos del Mes, N 376 (1990), p. 23, cons. $6^{\circ}$

${ }^{56}$ Corte de Apelaciones de Santiago, 22 de noviembre de 2000, Rol de Protección N 3934-2000, cons. $4^{\circ}$.

57 Se ha señalado que la culpa leve -que recae más estrictamente sobre el mandatario remuneradoen ciertos casos impondría al mandatario el deber de consultar expresamente a sus mandantes respecto del contenido del mandato. Así, tratándose de otros mandatos remunerados se ha sostenido que "el mandatario debía en despliegue de tal diligencia promotora y, a falta de estipulación expresa en el contrato, acerca de 
presente que el límite a su interpretación de las instrucciones radica en que, como se explicará, tiene vedado por ley ejercer funciones de árbitro entre los instructores. Este conjunto de razones evidencia que el notario no es del todo libre para cumplir las instrucciones como mejor le parezca y pone de relevancia, una vez más, la conveniencia de que el texto de las instrucciones sea lo más detallado posible evitando el uso de cláusulas ambiguas o contradictorias, de tal manera de restringir el campo de acción del notario y consecuencialmente evitar futuras discrepancias entre las partes.

\section{RESPONSABILIDAD DEL NOTARIO ${ }^{58}$ POR INCUMPLIMIENTO DE LAS INSTRUCCIONES}

El notario se encuentra sujeto a diversos estatutos de responsabilidad: i) la responsabilidad civil en caso de incurrir en actos u omisiones que ocasionen perjuicios a terceros, y ii) la responsabilidad criminal derivada de la configuración en su actuar de conductas tipificadas penalmente.. Siguiendo nuestra tesis en cuanto a que las instrucciones notariales constituyen mandatos, estimamos que civilmente la responsabilidad que se configurará será una de tipo contractual ${ }^{59}$ si el notario no cumple o cumple imperfecta o tardíamente las instrucciones, agravándose su responsabilidad por tratarse de un mandato remunerado. En efecto, recuérdese que el artículo 2129 del Código Civil señala que "el mandatario responde hasta de la culpa leve en el cumplimiento de su encargo. Esta responsabilidad recae más estrictamente sobre el mandatario remunerado". Pizarro comparte nuestra tesis de responsabilidad contractual agregando que en el evento que el notario falle en la vigilancia del estricto cumplimiento de las instrucciones la responsabilidad civil solo procederá si un notario estándar no hubiera cometido esa desatención o acto negligente ${ }^{60}$; el mismo autor luego agrega que es tarea

la distribución de los ingresos obtenidos, verificar o consultar expresamente con sus mandantes acerca de la forma de distribución. Tal era la conducta que le venía impuesta al mandatario de acuerdo con la diligencia media apreciada más estrictamente, que le resultaba exigible de conformidad al artículo 2129 del Código Civil", Brantt, M.-Mejías, C., "El contenido de la obligación del mandatario. La culpa y la indemnización de daños por el incumplimiento. Corte Suprema, 28 de enero de 2013, Rol No 5898-2012”, en Henríquez, I. (coord.), El Mandato. Ensayos doctrinarios y comentarios de jurisprudencia, LegalPublishing, Santiago, 2013, p. 131.

58 Acerca de responsabilidad de los notarios en general vid Pizarro, C., "La responsabilidad civil de los notarios en Chile", en Revista de Derecho Universidad Católica del Norte, Año 18 - N², 2011, pp. 137149; Mohor, E., "La Responsabilidad de Notarios y Conservadores", en Revista de la Asociación de Notarios y Conservadores, Asociación de Notarios y Conservadores, Santiago, 2000, No 9, pp. 9-39; Fernández, J., "Responsabilidad Civil de los Notarios", en Boletín de la Academia Vasca de Derecho, Año V, No. 14, Bilbao, diciembre 2007, pp. 73-107.

${ }^{59}$ Quienes estiman que las instrucciones notariales constituyen una función pública del notario, enfatizan la existencia de una responsabilidad "de tipo civil extracontractual o propiamente legal", Torrealba, V., $L a$ instrucción notarial: su naturaleza jurídica, Tesis para optar al grado de licenciado en derecho de la Pontificia Universidad Católica de Chile, 2001, pp. 34-35.

${ }^{60}$ Pizarro, C., "La responsabilidad civil de los notarios en Chile", en Revista de Derecho Universidad Católica del Norte, Año 18 - No 2, 2011, p. 146. 
de los tribunales diseñar ese modelo abstracto de conducta -lex artis- que permitirá inclinarse por el error o la culpa ${ }^{61}$.

\section{VALOR INTERPRETATIVO DE LAS INSTRUCCIONES.}

Debido a que las instrucciones notariales son suscritas generalmente por las mismas partes que han concurrido al otorgamiento de una escritura pública previa y versan sobre aspectos del mismo objeto cobra especial relevancia la norma de interpretación del artículo 1564 inciso $2^{\circ}$ del Código Civil que como se sabe dispone: "Podrán también interpretarse (las cláusulas de un contrato previo) por las de otro contrato (instrucciones) entre las mismas partes y sobre la misma materia”.

\section{IX. ¿ARBItraje DE FACTO?}

Hay un punto que nos merece especial preocupación. El Notario recibe instrucciones de partes que tienen intereses contrapuestos en lo que respecta al cumplimiento de las mismas, y cuando se trata de instrucciones complejas puede que dicho ministro de fe se vea en la necesidad de hacer calificaciones jurídicas y de resolver interpretaciones distintas que las partes hagan de ellas. Recordemos al efecto que el artículo 480 inciso $2^{\circ}$ del Código Orgánico de Tribunales expresamente señala: "Es prohibido a los notarios la aceptación y desempeño de arbitrajes y particiones”. Esto, señala Vidal, es una advertencia que debe tenerse presente cuando, como ocurre desgraciadamente las más de las veces, la carta o documento que contiene la Instrucción no es precisamente un modelo de claridad, de concisión, ni de manejo del lenguaje ${ }^{62}$.

Como dice Rosso, una de las cuestiones complejas en materia de instrucciones notariales dice relación con los conflictos que con posterioridad al otorgamiento de estas surgen entre las partes del acto principal, las que intentan convencer o demostrar al Notario que las instrucciones deben aplicarse en el sentido que a cada una más favorece. En esta situación, la decisión del Notario beneficiaría a un instructor y perjudicaría de modo inversamente proporcional al otro u otros ${ }^{63}$.

Enfrentado a instrucciones complejas el Notario podría convertirse de facto en árbitro, cuestión que le está prohibida por la norma citada. Una cosa es dar cumplimiento a las instrucciones y otra es entrar a dirimir cuestiones de índole jurídica para darles cumplimiento. Hay, a veces, una línea muy delgada entre una y otra, pero claramente

\section{${ }^{61}$ Ídem.}

${ }^{62}$ Vidal, I., El Estudio de los Títulos de Dominio. Segunda Parte, Editorial Fallos del Mes Ltda., Santiago, 2000, p. 20.

63 Rosso, G., "Instrucciones notariales como comisiones de confianza”, en Henríquez, I. (coord.), El Mandato. Ensayos doctrinarios y comentarios de jurisprudencia, LegalPublishing, Santiago, 2013, p. 89. 
un Notario debiera abstenerse de hacer lo último so pena de incurrir en la prohibición que le impone el Código Orgánico.

Al respecto y con el objeto de evitar estas situaciones el proyecto de ley referido sobre notarios y conservadores impone a los primeros una especie de examen preventivo para que haya correspondencia entre las instrucciones notariales y el contrato previo. En efecto, el inciso $4^{\circ}$ del artículo 439 ter que se incorpora al COT señala: Si el notario advierte discrepancia entre las cláusulas del contrato respectivo y las estipulaciones de las instrucciones o si dichas estipulaciones sobrepasan sus facultades, rebusará aceptarlas ${ }^{64}$. Así, si en una escritura pública de compraventa se declara pagado el precio de contado no podría posteriormente mediante instrucciones notariales señalarse que el precio se pagará a plazo en tantas cuotas.

Nótese que el proyecto solo se refiere a las eventuales discrepancias entre el contrato previo y las posteriores instrucciones, sin embargo, nada dice respecto de las controversias que puedan surgir por las interpretaciones contrapuestas que los instructores den a las mismas y que intentan imponer al notario al momento de su ejecución.

Es importante tener presente que ha sido una larga aspiración de los notarios el que se les permita contar con facultades para dirimir casos como estos. Así, respecto de las funciones como árbitro del notario, Vidal señala que es evidente que una actuación del notario en tal sentido, y cuando la ocasión es propicia para ello, sería útil para zanjar las inevitables interpretaciones parciales y antojadizas de las partes involucradas ${ }^{65}$. Agrega el mismo autor que el carácter de compromisario que asumiría el Notario tiene, además del fundamento de ya haber sido distinguido con la confianza de las partes de un contrato, una justificación que a todas luces aparece como lógica ya que, quién mejor que él puede conocer las reales (y a veces hasta las ocultas) intenciones de las partes cuando, después de leído el contrato y al suscribirlo, opinaron ante él y le manifestaron las inquietudes que tenían respecto al cumplimiento de las obligaciones inmediatas y que les obligaba a entregar las Instrucciones ${ }^{66}$. Así planteado, este escenario podría justificar otorgar facultades decisorias o de mediación al notario con el fin de evitar la judicialización de estas controversias, pero más allá de la actual prohibición legal de ser árbitros, creemos que existen poderosas razones para negar a los notarios tales facultades en futuras reformas. En efecto, respecto de las instrucciones, el notario no es sino uno de los contratantes (mandatario) y el principal obligado por las mismas, siendo así parte interesada en la controversia acerca de la interpretación de las instrucciones, lo que se contrapone a la ajenidad e imparcialidad que exigen tanto la función de árbitro como la de mediador.

Además, se ha afirmado que la proscripción de las facultades decisorias del Notario le impone un especial deber de cuidado al momento del otorgamiento de las instrucciones, ya que deberá evitar que, para dar cumplimientos a ellas llegado el momento

${ }^{64}$ Mensaje cit., p. 38.

${ }^{65}$ Vidal, I., El Estudio de los Títulos de Dominio. Segunda Parte, Editorial Fallos del Mes Ltda., Santiago, 2000, p. 20.

${ }^{66}$ Ídem, p. 21. Más argumentos pueden verse en Vidal, I., "El Notario, el Arbitraje y las Instrucciones", en Revista de la Asociación de Notarios y Conservadores de Chile, No 4, 1992, pp. 47-51. 
de restituir el depósito deba hacer calificaciones o interpretaciones de cláusulas de la escritura, materia que -en todo caso-corresponde a un tribunal y no a él ${ }^{67}$. En el mismo sentido, agrega Gaete que deberá evitarse aquella corriente frase "El Notario entregará los documentos si a su juicio se ha dado cumplimiento a lo estipulado", ya que a él no le corresponde emitir juicios; las calificaciones jurídicas y los hechos solo pueden ser conocidos y apreciados por un tribunal ${ }^{68}$.

Nada de lo dicho en todo caso se opone a que el notario aporte su experiencia e imparcialidad al momento de fijar los términos de las instrucciones, de modo que estas contengan las precisiones necesarias para plasmar correctamente la voluntad de las partes, cumplir su cometido y evitar futuras disputas. Sin embargo, una vez otorgadas no parece adecuado que su interpretación recaiga en el notario instruido, es decir, el principal obligado por las mismas.

En conclusión, las controversias que se presenten entre las partes relativas al cumplimiento de las instrucciones no pueden -ni deben- ser resueltas por el notario, y si este las ejecutare en forma tal que alguno de los instructores se sienta perjudicado podrá en su calidad de mandante ejercer las acciones judiciales derivadas del incumplimiento de obligaciones contractuales ${ }^{69}$.

\section{Actos que no pueden Ser objeto de instrucciones}

Si bien las instrucciones pueden en principio tener un objeto amplio, el proyecto de ley sobre notarios y conservadores en el inciso $6^{\circ}$ del artículo 439 ter que se incorpora al COT dispone que las instrucciones i) no podrán contener vulneración alguna al interés fiscal o ii) la realización de contratos simulados ${ }^{70}$.

Nos parece que estos dos límites se justifican pues pretenden resguardar el interés fiscal y evitar el perjuicio de terceros, cuestión de común ocurrencia en los contratos simulados. Respecto de lo primero, piénsese por ejemplo si en la escritura pública se dijese que el precio de venta es tanto y en las instrucciones se señalara como valor real uno superior para así evitar justificar ante las autoridades tributarias los recursos con que se financia el verdadero valor de adquisición de un determinado bien ${ }^{71}$. En tal caso

${ }^{67}$ Gaete, E., Actas Notariales. Parte General, Ediciones Jurídicas La Ley, Santiago, 1993, p. 121-122.

68 Ídem, p. 122.

${ }^{69}$ En la práctica es habitual que la parte que se siente perjudicada por el modo en que el Notario cumpla las instrucciones recurra de protección alegando la vulneración del art. 19 N 24 de la Constitución Política (afectación de derechos emanados de los contratos), como lo prueba la jurisprudencia citada en este trabajo.

${ }^{70} \mathrm{El}$ proyecto de ley se inspira aquí en las palabras de Gaete que al referirse a las instrucciones notariales señala que "el Notario deberá poner especial cuidado en lo relativo a la licitud de la actuación, evitando por ejemplo la burla del interés fiscal, o la realización de contratos simulados”. Gaete, E., Actas Notariales. Parte General, Ediciones Jurídicas La Ley, Santiago, 1993, p. 121.

${ }^{71}$ Gaete advierte la misma figura de evasión tributaria, en especial en aquellos casos en que el notario recibe documentación en sobres cerrados, recomendando la prohibición de este último tipo de instrucciones. Ídem, p. 55 . 
(subvaluación) el notario debiera abstenerse de aceptar tales instrucciones, pues eventualmente podría verse afectado el interés fiscal. Igual actitud debiera adoptar, verbi gratia, si una instrucción diere cuenta de una donación disimulada detrás de una aparente compraventa previa celebrada por escritura pública (habría simulación y seguramente algún perjudicado).

Fuera de estos límites también estimamos que no debiesen admitirse instrucciones notariales para modificar ciertas cláusulas de un contrato cuya solemnidad es la escritura pública, como se explicará en el siguiente apartado.

Los asuntos que los instructores-partes pueden encargar al notario, tampoco-como todo acto jurídico- pueden ser de aquellos prohibidos por la ley ni contrarios a las buenas costumbres o al orden público (artículos 1445 números $3^{\circ}$ y $4^{\circ}, 1461$ inciso final, 1466 parte final, del Código Civil). En casos como los señalados, la negativa del notario aparece como totalmente justificada atendido que en todos ellos es posible advertir que las instrucciones estarán afectadas por un vicio que les restará eficacia.

\section{EFICACIA ENTRE LAS PARTES DE MODIFICACIONES EFECTUADAS MEDiANTE INSTRUCCIONES NOTARIALES A CIERTAS CLÁUSULAS DE UN CONTRATO CUYA SOLEMNIDAD ES LA ESCRITURA PÚBLICA}

La Corte Suprema refiriéndose en general a los instrumentos privados (las instrucciones notariales lo son) usados para modificar cláusulas de un contrato cuya solemnidad es la escritura pública ha sostenido que en un contrato solemne, como el de compraventa de un bien raíz, debe diferenciarse entre las solemnidades que la ley requiere para su celebración y las obligaciones que derivan de ese contrato y que no se refieren al inmueble en sí mismo. Las obligaciones personales, en cuanto a la forma y plazo de la entrega material de lo vendido y las modalidades en el pago del saldo de precio, si las hubiere, han de distinguirse de cualquier alteración que se desee efectuar acerca de la individualidad del inmueble vendido, su cabida, etc. Para modificar aquellas obligaciones la ley no ha exigido las solemnidades requeridas para la venta y basta para su eficacia legal entre las partes un simple acuerdo entre ellas. En consecuencia, tiene eficacia legal un documento privado reconocido o tenido como tal que modifica una de las obligaciones personales emanadas de la compraventa de un bien raíz, como es la forma de pagar el saldo de precio de una manera distinta a la acordada en el contrato solemne original ${ }^{72}$.

En otras palabras, modificar cláusulas relativas al inmueble mismo necesariamente requiere el otorgamiento de la correspondiente escritura pública, sin que ello sea posible mediante instrucciones notariales, debido a su carácter de instrumentos privados.

En línea con esta jurisprudencia y en particular respecto de las instrucciones notariales la Corte Suprema reconoció que las mismas pueden tener valor probatorio suficiente para acreditar la falta de verdad o de exactitud de declaraciones contenidas en

\footnotetext{
${ }^{72}$ Corte Suprema, Rol No 11.789, 27 de abril de 1976, Fallos del Mes, No 209 (1976), p. 37, cons. $5^{\circ}$ y $6^{\circ}$.
} 
una escritura pública. En el caso que pasa a comentarse, el máximo tribunal confirmó la nulidad alegada por el vendedor respecto de un contrato de compraventa de un bien inmueble por falta de acuerdo en el precio fundado en que mientras la escritura señalaba que se había pagado de contado, las instrucciones notariales dadas por el comprador, en cambio, decían que se pagaría en cuotas, no coincidiendo por lo demás ambas cantidades. La Corte resolvió: Que los jueces de la instancia, al analizar entonces, y ponderar en la especie, lo declarado por las partes, en la escritura de compraventa del predio El Purgatorio, en lo referente al precio de esta negociación, frente, asimismo, al mérito de las pruebas rendidas acerca de la falta de tal acuerdo sobre el particular, y especialmente ante la trascendencia y valor de las instrucciones escritas que el comprador dejara al Notario sobre el monto y manera de pagar el precio de esa operación comercial aparece que esos sentenciadores actuaron dentro de sus facultades exclusivas para apreciar tales probanzas; y que al resolver que esos antecedentes evidenciaban que entre las partes no bubo acuerdo acerca del precio real de la compraventa adoptaron resolución apreciando el mérito de aquellas probanzas sobre tales hechos discutidos... ${ }^{73}$.

Al razonamiento del más alto tribunal habría que agregar -para dar prevalencia a las instrucciones por sobre lo declarado en la escritura- lo dispuesto en el artículo 428 del Código de Procedimiento Civil en el sentido que entre dos o más pruebas contradictorias, y a falta de ley que resuelva el conflicto, los tribunales preferirán la que crean más conforme a la verdad, pues como dice Sepúlveda parece razonable encontrar más conforme a la verdad lo declarado en las contraescrituras, ya que si las partes alteran lo señalado en una escritura pública es porque estiman que esta no guarda relación con la realidad ${ }^{74}$. Concordamos con el autor citado en cuanto a que también se debe tener presente que, en la práctica, en muchas escrituras de compraventa, a pesar de indicarse pagado el precio, se hace mención de que este se deja con instrucciones notariales. En esta última situación, a diferencia de cuando se dice pagado el precio y nada más, debido a que se trata de una declaración contenida en la misma escritura pública de compraventa, lo acordado en las instrucciones puede llegar a producir efectos, incluso, contra terceros y estos no podrían alegar desconocimiento de las declaraciones contenidas en las instrucciones. En este caso no resulta aplicable lo prescrito en el inc. $2^{\circ}$ del art. 1876 del CC, sino que se vuelve a la regla general contenida en su inc. $1^{\circ 75}$.

El hecho que las instrucciones notariales más comunes se refieran a la forma $\mathrm{u}$ oportunidad de pago del precio en una compraventa de inmuebles es lo que explica -en armonía con lo resuelto por la Corte Suprema- que en la mayoría de las veces sea suficiente y se use solo el otorgamiento de simples instrumentos privados para plasmar las instrucciones.

${ }^{73}$ Corte Suprema, Rol No 12.669, 1 de diciembre de 1977, Fallos del Mes, No 229 (1977), p. 353, cons. $9^{\circ}$.

${ }^{74}$ Sepúlveda, M., "Efectos de lo previsto en el artículo 1876 inciso $2^{\circ}$ del Código Civil y las instrucciones notariales", en Temas de Derecho (Universidad Gabriela Mistral), Año XVIII, Nos. 1 y 2 (2003), p. 56. En términos similares Cruz, N., Curso de Derecho Notarial, Santiago, 1984, p. 392.

75 Sepúlveda, ob. cit., pp. 56-57. 


\section{CONCLUSIONES FinAles}

A causa del intenso uso que se hace en la práctica de las instrucciones notariales y la ausencia de legislación acerca de ellas, resulta imperioso su regulación.

Sostenemos que las instrucciones constituyen un mandato al Notario y por su carácter contractual este tiene libertad para aceptarlas. Pueden otorgarlas una o ambas partes que concurrieron al contrato previo, pero en el primer supuesto no son vinculantes lógicamente para la otra, pero ello no significa que pueda revocarlas si está comprometido el interés de un tercero $(v, g r$., instrucciones otorgadas por el comprador en que el interés del tercero es el precio que la parte vendedora espera recibir).

En vista de que las instrucciones son un mandato, si el Notario no las cumple o cumple imperfectamente surge para él una responsabilidad de tipo contractual.

Mediante las instrucciones notariales las partes pueden modificar determinadas cláusulas de un contrato cuya solemnidad es la escritura pública. Así, pueden modificar el precio o forma de pago pactado en una escritura pública previa (pero no los deslindes de un predio), según se explicó.

Las instrucciones notariales tienen un importante valor interpretativo, pues se trata de instrumentos suscritos entre las mismas partes y respecto de la misma materia en relación con un contrato previo.

Finalmente, es necesario tener presente que las instrucciones no pueden convertir de facto al Notario en árbitro -cuestión que le está prohibida- de ahí la necesidad de ser extremadamente claros y precisos en su redacción.

\section{BIBLIOGRAFÍA}

Abeliuk M., René, Las Obligaciones, LegalPublishing, Santiago, 2014.

Alessandri R., Arturo, De las Obligaciones, Santiago, 1930.

Brantt Zumarán, María Graciela y Mejías Alonzo, Claudia, "El contenido de la obligación del mandatario. La culpa y la indemnización de daños por el incumplimiento. Corte Suprema, 28 de enero de 2013, Rol N 5898-2012”, en Henríquez, I. (coord.), El Mandato. Ensayos doctrinarios y comentarios de jurisprudencia, LegalPublishing, Santiago, 2013, pp. 113-165.

Claro Solar, Luis, Explicaciones de Derecho Civil Chileno y Comparado, t. XII, Santiago, 1939.

Cruz Barrios, Norman, Curso de Derecho Notarial, Santiago, 1984.

Díaz Mieres, Luis, Derecho Notarial Chileno, Editorial Jurídica de Chile, Santiago, 1983.

Fernández Hierro, José Manuel, "Responsabilidad Civil de los Notarios", en: Boletín de la Academia Vasca de Derecho, Año V, No 14, 2007, pp. 73-107.

Figueroa Yáñez, Gonzalo, Repertorio de Legislación y Jurisprudencia Chilenas, Código Civil y Leyes Complementarias, T. VI, Editorial Jurídica de Chile, Santiago, 1997.

Gaete González, Eugenio, Actas Notariales. Parte General, Editorial La Ley, Santiago, 1993.

GiméneZ-Arnau, Enrique, Derecho Notarial Español, v. 3, Editorial Universidad de Navarra, 1965.

GonZÁlEZ CASTILlo, Joel, "Mandatos irrevocables: un cuestionamiento a su general aceptación”, en Elorriaga, F. (coord.), Estudios de Derecho Civil VII, LegalPublishing, Santiago, 2012, pp. 351-360.

López Santa María, Jorge, Los Contratos. Parte General, T. I, Editorial Jurídica de Chile, Santiago, 2005. 
Mohor Albornoz, Elías, "La Responsabilidad de Notarios y Conservadores", en Revista de la Asociación de Notarios y Conservadores, No 9, 2000, pp. 9-39.

Pizarro Wilson, Carlos, "La responsabilidad civil de los notarios en Chile", en Revista de Derecho Universidad Católica del Norte, Año 18 - No 2, 2011, pp. 137-149.

Riveros Ferrada, Carolina, "El principio general de la buena fe en el contrato de mandato. Comentario a la sentencia de la Corte Suprema de 30 de mayo de 2012, Rol No 5229-09”, en Henríquez, I. (coord.), El Mandato. Ensayos doctrinarios y comentarios de jurisprudencia, LegalPublishing, Santiago, 2013, pp. 207-218.

Rosso, Gian Franco, “Instrucciones notariales’ como comisiones de confianza”, en Henríquez, I. (coord.), El Mandato. Ensayos doctrinarios y comentarios de jurisprudencia, LegalPublishing, Santiago, 2013, pp. 77-95.

SÁENZ de SANTA María, Fernando, Extralimitación del mandatario, en AA.VV., Contratos, Editorial Jurídica de Chile, Santiago, 1991, pp. 37-44.

Santa Cruz, Víctor, "El instrumento público", en Revista de Derecho y Jurisprudencia, t. 39, primera parte, 1942, pp. 33-60.

Sepúlveda larroucau, Marco Antonio, "Efectos de lo previsto en el artículo 1876 inciso $2^{\circ}$ del Código Civil y las instrucciones notariales", en Temas de Derecho (Universidad Gabriela Mistral), Año XVIII, Nos. 1 y 2, 2003, pp. 35-57.

Sepúlveda Larroucau, Marco Antonio, Estudio de títulos de inmuebles, Editorial Metropolitana, Santiago, 2002.

Sepúlveda Larroucau, Marco Antonio, Temas de Derecho Inmobiliario, Editorial Metropolitana, Santiago, 2006.

Stitchkin, David, El Mandato Civil, Editorial Jurídica de Chile, Santiago, 2013.

Vidal Domínguez, Ignacio, El Estudio de los Títulos de Dominio. Segunda Parte, Editorial Fallos del Mes Ltda., Santiago, 2000.

Vidal Domínguez, Ignacio, El Estudio de los Títulos de Dominio, T. I, El Jurista, Santiago, 2012.

Vidal DomíngueZ, Ignacio, "El Notario, el Arbitraje y las 'Instrucciones”, en Revista de la Asociación de Notarios y Conservadores de Chile, $\mathrm{N}^{\circ} 4$, 1992, pp. 47-51.

Vidal Olivares, Álvaro y Brantt Zumarán, María Graciela (2013), "Obligación, incumplimiento y responsabilidad civil del mandatario en el Código Civil chileno”, en Revista Chilena de Derecho, vol. 40, No 2, 2013, pp. 413-431. 